Check for updates

Cite this: RSC Adv., 2018, 8, 39967

\title{
A gel single ion conducting polymer electrolyte enables durable and safe lithium ion batteries via graft polymerization
}

\author{
Yazhou Chen, ${ }^{a}$ Guodong Xu, (D) ${ }^{\mathrm{b}}$ Xupo Liu, ${ }^{a}$ Qiyun Pan, ${ }^{a}$ Yunfeng Zhang, (D) a \\ Danli Zeng, ${ }^{a}$ Yubao Sun, (D) *a Hanzhong Ke ${ }^{\star a}$ and Hansong Cheng ${ }^{a}$
}

Concentration polarization issues and lithium dendrite formation, which associate inherently with the commercial dual-ion electrolytes, restrict the performance of lithium ion batteries. Single ion conducting polymer electrolytes (SIPEs) with high lithium ion transference numbers $\left(t_{+} \approx 1\right)$ are being intensively studied to circumvent these issues. Herein, poly(ethylene-co-vinyl alcohol) (EVOH) is chosen as the backbone and then grafted with lithium 3-chloropropanesulfonyl(trifluoromethanesulfonyl)imide (LiCPSI) via Williamson's reaction, resulting in a side-chain-grafted single ion polymer conductor (EVOH-graft-LiCPSI). The ionomer is further blended with poly(vinylidene fluoride-co-hexafluoropropylene) (PVDF-HFP) by solution casting for practical use. The SIPE membrane with ethylene carbonate and dimethyl carbonate (EC/DMC =1:1, v/v) as plasticizer (i.e., gel SIPE) exhibits an ionic conductivity of $5.7 \times 10^{-5} \mathrm{~S} \mathrm{~cm}^{-1}$, a lithium ion transference number of 0.88 , a wide electrochemical window of $4.8 \mathrm{~V}\left(\mathrm{vs}\right.$. Li/Li $\left.{ }^{+}\right)$and adequate mechanical strength. Finally, the gel SIPE is applied in a lithium ion battery as the electrolyte as well as the separator, delivering an initial discharge capacity of $100 \mathrm{~mA} \mathrm{~h} \mathrm{~g}^{-1}$ at $1 \mathrm{C}$ which remains at $95 \mathrm{~mA} \mathrm{~h} \mathrm{~g}^{-1}$ after 500 cycles.

Received 11th September 2018 Accepted 13th November 2018

DOI: $10.1039 / c 8 r a 07557 c$

rsc.li/rsc-advances lithium cations with the heteroatoms such as $\mathrm{N}$ or $\mathrm{O}$ in the polymer matrix further lower the ion transference number of dual-ion polymer electrolytes. ${ }^{\mathbf{8} 9}$ It causes a serious concentration polarization at the electrolyte/electrodes interface, restricting the high performance of lithium ion batteries especially at high current density. ${ }^{\mathbf{1 0 , 1 1}}$

To circumvent these problems, single ion conductors with high lithium ion transference number $\left(t_{+} \approx 1\right)$ have been proposed to be utilized in lithium ion batteries, due to the intrinsic ability to significantly reduce the concentration polarization and restrict the growth of lithium dendrites during cycle performance..$^{12-14}$ As for single ion conductors, the anions are covalently tethered onto polymer or inorganic backbones, which restricts the mobility of anions to maximize the transference number of lithium ions. ${ }^{\mathbf{9}, 15}$ Among them, ceramic electrolyte with high ionic conductivity at room temperature have captured much attention. ${ }^{16-18}$ However, the large interfacial resistance arising from the poor interfacial compatibility between the rigid ceramic and electrode materials cannot be completely solved in a short time, ${ }^{19-22}$ which makes it difficult to be applied in lithium ion batteries on a large scale. On the contrary, solid-state SIPE possesses the advantages of lighter weight and higher flexibility compared to the ceramic electrolytes, which is regarded as a better candidate. ${ }^{12}$ Unfortunately, the ionic conductivity of solid-state SIPEs is usually lower than the dual-ion polymer electrolytes, because the mobility of the lithium ion in the polymer matrix is difficultly at room temperature. $^{23}$
${ }^{a}$ Sustainable Energy Laboratory, Faculty of Material Science and Chemistry, China University of Geosciences (Wuhan), 388 Lumo RD, Wuhan 430074, China. E-mail: sunyubao@gmail.com; kehanz@163.com; Tel: +8613377851282

${ }^{b}$ School of Chemistry and Environmental Engineering, Yancheng Teachers University, No. 2, Xiwang Avenue, Yancheng, 224007, Jiangsu Province, China 
An effective strategy to achieve high ionic conductivity is to saturate the SIPEs with appropriate organic solvents as plasticizers to facilitate lithium ion solvation and transport. ${ }^{24-27}$ In this regard, gel SIPE successfully combines the advantages of solid-state and liquid electrolytes, resulting in high ionic conductivity and excellent compatibility with electrodes. ${ }^{28,29}$ In the past several years, a variety of gel SIPEs based on $\mathrm{sp}^{3}$ hybrid boron,,$^{28,29}$ bis sulfonyl imide $\mathrm{e}^{30,31}$ and sulfonate ${ }^{32,33}$ has been reported. For instance, Porcarelli et al. ${ }^{24}$ presented a simple method to prepare a cross-link gel SIPE via in situ radical copolymerization and the ionic conductivity was significantly enhanced compared to the dry state. Cui et al. ${ }^{34}$ developed a couple of $\mathrm{sp}^{3}$ hybrid boron based gel SIPEs and the assembled cell performed well at room temperature. These works have shown that gel SIPEs have great application potential in lithium ion batteries. However, most of the batteries utilizing gel SIPEs display poor cycling battery performance..$^{24,35-37}$ Therefore, it is urgent and meaningful to develop novel gel SIPE by exploring other effective functional groups or polymer backbones.

In this work, a functional group of LiCPSI was synthesized and then grafted covalently on EVOH to immobilize the anions via Williamson's reaction as illustrated in Scheme 1. The LiCPSI was designed without unsaturated $\mathrm{C}=\mathrm{C}$ bonds to enhance the electrochemical stability. ${ }^{38}$ Meanwhile, the flexible EVOH served as main chain to enable the excellent thermal and chemical stability. Thus, a side-chain grafted single ion polymer conductor (EVOH-graft-LiCPSI) was obtained. The SIPE blend film was prepared through blending the EVOH-graft-LiCPSI with the PVDF-HFP via solution cast method. The morphologies, thermal stability, mechanical strength and electrochemical properties of the gel SIPE have been investigated systematically.

\section{Experimental section}

\subsection{Materials}

Trifluoromethanesulfonamide and 3-chloropropanesulfonyl chloride were purchased from Aldrich and used without further purification. Acetonitrile, purchased from Aladdin, was dried with $\mathrm{P}_{2} \mathrm{O}_{5}$ and distilled under argon atmosphere at reduced pressure. Anhydrous lithium hydroxide $(\mathrm{LiOH})$ and lithium hydride ( $\mathrm{LiH})$ were purchased from Aladdin. Dichloromethane and $N$-methyl-2-pyrrolidone (NMP, AR) were purchased from Sinopharm Chemical Reagent Co., Ltd. Mixed organic solvent of
EC and DMC (v/v, 1/1) was purchased from Dodo Chem Co., Ltd. Poly(ethylene-co-vinyl alcohol) (EVOH) was purchased from Japan STS (average $M_{\mathrm{w}} \sim 300000$, ethylene $35 \mathrm{wt} \%$ ) and dried under vacuum at $80{ }^{\circ} \mathrm{C}$ for $12 \mathrm{~h}$ before use. Poly(vinylidene fluoride-co-hexafluoropropylene) (PVDF-HFP) was purchased from Sigma Aldrich Co., Ltd. (average $M_{\mathrm{w}} \sim 400000$, average $M_{\mathrm{n}}$ $\sim 130$ 000). $\mathrm{LiFePO}_{4}$ (LFP) was obtained from Tianjin STL Energy Technology Co. Ltd.

\subsection{Synthesis of lithium 3-chloropropanesulfonyl(trifluoromet- hanesulfonyl)imide (LiCPSI)}

LiCPSI was synthesized according to the previous work. ${ }^{39}$ $2.034 \mathrm{~g}$ anhydrous lithium hydroxide and $6.314 \mathrm{~g}$ trifluoromethanesulfonamide were transferred into a $100 \mathrm{~mL}$ twonecked flask and placed in ice bath. $45 \mathrm{~mL}$ of dry acetonitrile as the solvent was added and the solution was stirred under argon protection. Then, $7.5 \mathrm{~g}$ 3-chloropropanesulfonyl chloride was slowly added via a dropping funnel. Afterwards, the reaction mixture was raised slowly to room temperature and left to react for 24 hours. The mixture was filtered and the filtrate was concentrated under vacuum to give faintly yellow solid. The product was further purified by recrystallizing in dichloromethane to obtain a pure white solid with an over $\sim 72 \%$ yield.

\subsection{Synthesis of single ion polymer conductor (EVOH-graft- LiCPSI)}

As shown in Scheme 1, $1 \mathrm{~g}$ of EVOH was dissolved in $20 \mathrm{~mL}$ of anhydrous DMAC with magnetic stirring at $25{ }^{\circ} \mathrm{C}$ to form a transparent solution. Then, $0.63 \mathrm{~g}$ of $\mathrm{LiH}$ was added under argon atmosphere. The reaction mixture was stirring for 3 hours followed by adding $2.2 \mathrm{~g}$ of LiCPSI, and further heated up to $80^{\circ} \mathrm{C}$ for 6 hours. The solution was concentrated on a rotary evaporator and purified by dialysis against water for 3 days. Upon solvent removal, the EVOH-graft-LiCPSI was dried at $80{ }^{\circ} \mathrm{C}$ for 24 hours.

\subsection{Characterization}

1-Dimensional proton Nuclear Magnetic Resonance $\left({ }^{1} \mathrm{H}\right.$ NMR) spectroscopy of the compound was conducted on a $400 \mathrm{MHz}$ NMR instrument (AVANCE III HD $400 \mathrm{MHz}$, Swiss BRUKER) with $\mathrm{d}_{6}$ DMSO as solvent at room temperature. Fourier Transform Infrared (FTIR) spectroscopy of the sample was investigated by a spectrophotometer (VERTEX 70 FTIR, Germany BRUKER) with the range
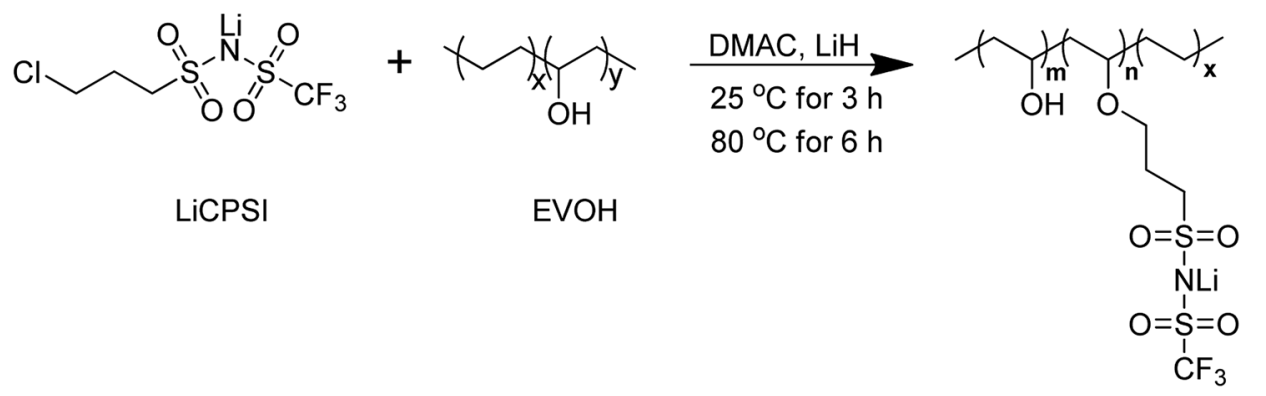

EVOH-graft-LiCPSI

Scheme 1 The synthetic route of EVOH-graft-LiCPSI. 
from $4000 \mathrm{~cm}^{-1}$ to $750 \mathrm{~cm}^{-1}$ at room temperature. Thermogravimetric analysis of the electrolyte was evaluated by STA 409 PC (Germany NETZSCH) from ambient temperature to $600{ }^{\circ} \mathrm{C}$ with the heating rate of $10{ }^{\circ} \mathrm{C} \mathrm{min}^{-1}$ under nitrogen atmosphere. The surface morphology of the blend membrane was probed by the scanning electron microscopy (SEM, SU8010, HITACHI). The prepared SIPE membrane was coated with gold in vacuum for $120 \mathrm{~s}$ prior to observation. Tensile strength of the blend film was measured with an electronic tensile tester (XLW (PC), Labthink, China) at room temperature.

\subsection{Preparation of the SIPE membrane}

The SIPE membrane was prepared via a solution casting method. ${ }^{40}$ Firstly, $0.1 \mathrm{~g}$ EVOH-graft-LiCPSI and 0.1 PVDF-HFP were added into $2 \mathrm{~mL} \mathrm{NMP}$ to obtain a homogeneous solution after stirring for 24 hours at $60{ }^{\circ} \mathrm{C}$. Then, the solution was subsequently cast onto a glass plate with an area of $20 \mathrm{~cm}^{2}$ followed by the solvent evaporation at $60{ }^{\circ} \mathrm{C}$ for several hours. After that, the SIPE membrane was peeled off from the glass plate and punched into small circles with a diameter of $19 \mathrm{~mm}$. The SIPE membrane was further dried at $60{ }^{\circ} \mathrm{C}$ for 48 hours under vacuum. The gel SIPE was made by soaking certain amount of mixture solvent of EC/DMC (v/v, $1: 1)$ without any additives in an argon filled glove box.

\subsection{Solvent uptake of the SIPE membrane}

Solvent uptake of the SIPE was measured by an improved weight method. ${ }^{41}$ The as-prepared SIPE was immersed in organic solvent of EC and DMC (v/v, 1/1) and weighted in the interval of 2 hours. The solvent uptake of the SIPE was calculated according to the eqn (1):

$$
\text { Solvent uptake }=\frac{w_{\mathrm{i}}-w_{0}}{w_{0}} \times 100 \%
$$

where $w_{\mathrm{i}}$ and $w_{0}$ stand for the weights of the wet and the dry SIPEs, respectively. Mean solvent uptake was obtained as the average of three samples to reduce errors.

\subsection{Electrochemical characterizations}

2.7.1 Ionic conductivity. Ion conductivity of the gel SIPE was measured via Electrochemical Impedance Spectroscopy (EIS) on a VMP3 electrochemical workstation by applying a $5 \mathrm{mV}$ perturbation from $1 \mathrm{MHz}$ to $100 \mathrm{mHz}$ at the open circuit potential. The as-prepared gel SIPE was sandwiched between two stainless steel to assemble a symmetrical "SS $|\mathrm{SIPE}| \mathrm{SS}$ " cell. The measurement was carried out between 25 and $80{ }^{\circ} \mathrm{C}$ with an interval of $10{ }^{\circ} \mathrm{C}$. Ionic conductivity was calculated using eqn (2):

$$
\sigma=\frac{l}{R A}
$$

where $l$ stands for the thickness of SIPE measured by a screw micrometer, $A$ represents the area of the SIPE, $R$ belongs to the bulk resistance, which was obtained from Nyquist plot and fitted with Z-View software.

2.7.2 Ion transference number. Lithium-ion transference number was investigated via the symmetrical "Li|SIPE $\mid \mathrm{Li}$ " cell on a VMP3 electrochemical workstation with a static potential polarization of $10 \mathrm{mV}$. The value of lithium ion transference number $\left(t_{+}\right)$was calculated from the combination of complex impedance and potentiostatic polarization methods as proposed by Evans et al. ${ }^{42}$ using eqn (3):

$$
t_{+}=\frac{I_{\mathrm{S}}\left(\Delta V-I_{0} R_{0}\right)}{I_{0}\left(\Delta V-I_{\mathrm{S}} R_{\mathrm{S}}\right)}
$$

where $\Delta V$ is the potential applied across the cell, $I_{0}$ and $I_{\mathrm{S}}$ are the initial and steady-state currents, and $R_{0}$ and $R_{\mathrm{S}}$ represent the initial resistance and the steady-state resistance of the passivation layers on the lithium electrode, respectively.

2.7.3 Electrochemical window. Electrochemical window of the SIPE was recorded in a "Li|SIPE|SS" cell on a VMP3 electrochemical workstation. Linear sweep voltammetry was conducted from $0 \mathrm{~V}$ to $6.0 \mathrm{~V}\left(v s . \mathrm{Li} / \mathrm{Li}^{+}\right)$at a constant rate of $1 \mathrm{mV} \mathrm{s}^{-1}$.

\subsection{Battery test}

The $\mathrm{LiFePO}_{4}$ composite cathode was prepared via a conventional casting method..$^{43} 0.08 \mathrm{~g}$ of EVOH-graft-LiCPSI was dissolved in $1 \mathrm{~mL}$ of NMP. Then, $0.24 \mathrm{~g}$ of $\mathrm{LiFePO}_{4}$ and $0.08 \mathrm{~g}$ of acetylene black were added. The single ion conductor used as binder is to construct ion transport channel and reduce the interfacial resistance between the cathode and gel SIPE. ${ }^{43}$ The mixture was stirred 12 hours at room temperature to obtain homogeneous slurry, and then coated on an aluminum foil with a doctor blade. After drying in the oven, the cathode film was cut into circles with a diameter of $15 \mathrm{~mm}$ and further dried at $80{ }^{\circ} \mathrm{C}$ under vacuum for 12 hours. The active materials loading of the cathode film is around $0.8 \mathrm{mg} \mathrm{cm}^{-2}$. The 2025 coin-type cells were assembled in an argon filled glove box. After assembling, the cell was kept at $60{ }^{\circ} \mathrm{C}$ for 6 hours to ensure completely infiltration of carbonate solvents and well contact at the interfaces. The battery performances were evaluated by Land at various C-rates within the discharge and charge cut-off voltages of $2.5 \mathrm{~V}$ and $4.2 \mathrm{~V}$ at $25{ }^{\circ} \mathrm{C}$.

\section{Results and discussion}

\subsection{Characterizations}

Fig. 1a represents the typical FTIR spectra of EVOH. The peak at $3300 \mathrm{~cm}^{-1}$ is assigned to the stretch vibration of $\mathrm{O}-\mathrm{H}$ groups. The peaks at $2865 \mathrm{~cm}^{-1}$ and $2926 \mathrm{~cm}^{-1}$ are ascribed to the antisymmetric and symmetric $\mathrm{C}-\mathrm{H}$ stretching vibration of the $\mathrm{CH}_{2}$ groups. For LiCPSI (Fig. 1b), the peaks at $1326 \mathrm{~cm}^{-1}$, $1193 \mathrm{~cm}^{-1}$ and $1120 \mathrm{~cm}^{-1}$ are attributed to the asymmetric and symmetrical stretching of $-\mathrm{SO}_{2}-$, stretching of $-\mathrm{S}-\mathrm{N}-$ and stretching of $-\mathrm{S}-\mathrm{N}-\mathrm{S}-$, respectively. As expected, the infrared characteristic peaks of the bis sulfonyl imide functional group at around $1326 \mathrm{~cm}^{-1}, 1193 \mathrm{~cm}^{-1}$ and $1120 \mathrm{~cm}^{-1}$ appear upon grafting (Fig. 1c). The results indicate that both LiCPSI and EVOH-graft-LiCPSI were successfully synthesized. However, the presence of $\mathrm{O}-\mathrm{H}$ stretching vibration at $3300 \mathrm{~cm}^{-1}$ suggests the grafted degree is not $100 \%$.

To further examine the chemical structure of LiCPSI and EVOH-graft-LiCPSI, ${ }^{1} \mathrm{H}$ NMR analysis was conducted (Fig. 2). As for pristine EVOH (Fig. 2a), peak 'a' (1.2-1.5 ppm) is assigned to 


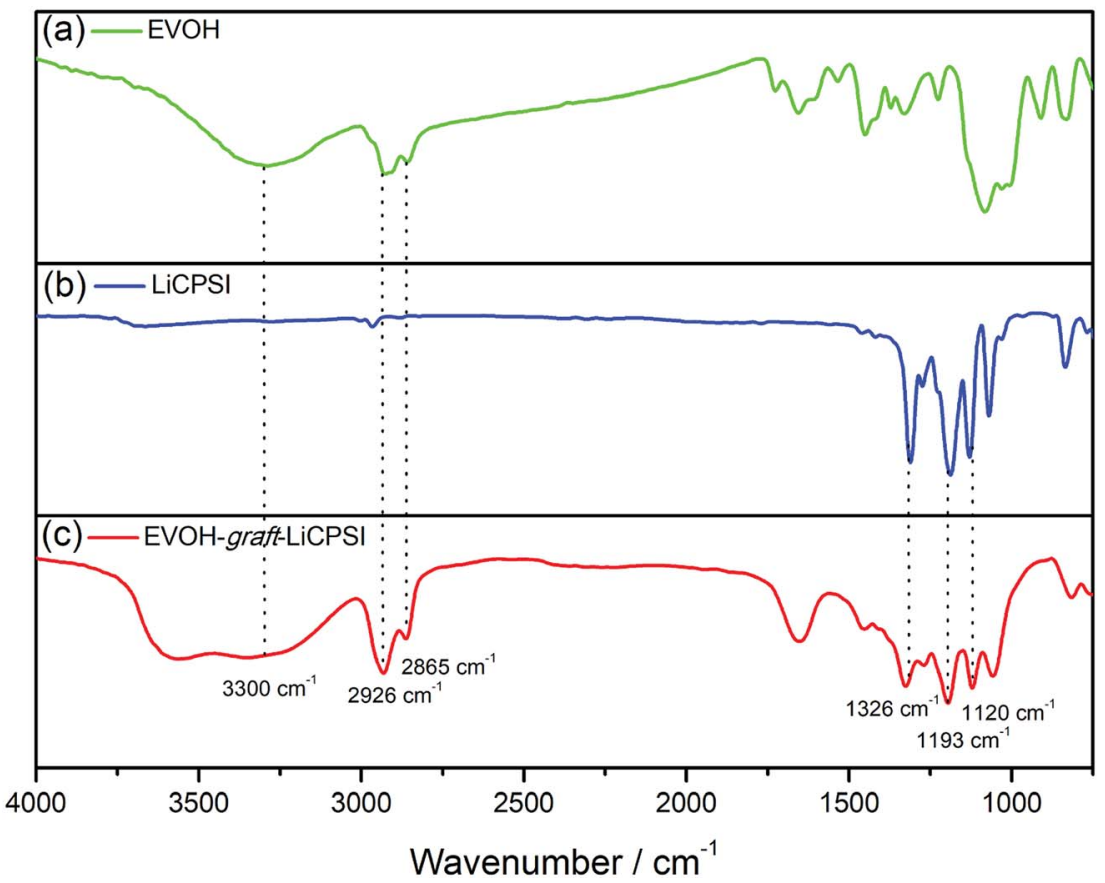

Fig. 1 The FT-IR spectra. (a) EVOH, (b) LiCPSI and (c) EVOH-graft-LiCPSI.

the methylene proton. Peak ' $b$ ' (3.6-3.9 ppm) represents the methine proton. Peak 'c' (4.0-4.5 ppm) is ascribed to protons of hydroxyl. As for LiCPSI (Fig. 2b), peak 'a' (3.74 ppm), 'b' (3.10 $\mathrm{ppm}$ ) and ' $\mathrm{c}$ ' (2.15 ppm) represent the three types of methylene proton of $\mathrm{Cl}-\mathrm{CH}_{2}, \mathrm{CH}_{2}-\mathrm{SO}_{2}$ and $-\mathrm{CH}_{2}-$, respectively. As for EVOH-graft-LiCPSI (Fig. 2c), peak ' $a$ ', 'b' and 'c' stand for the

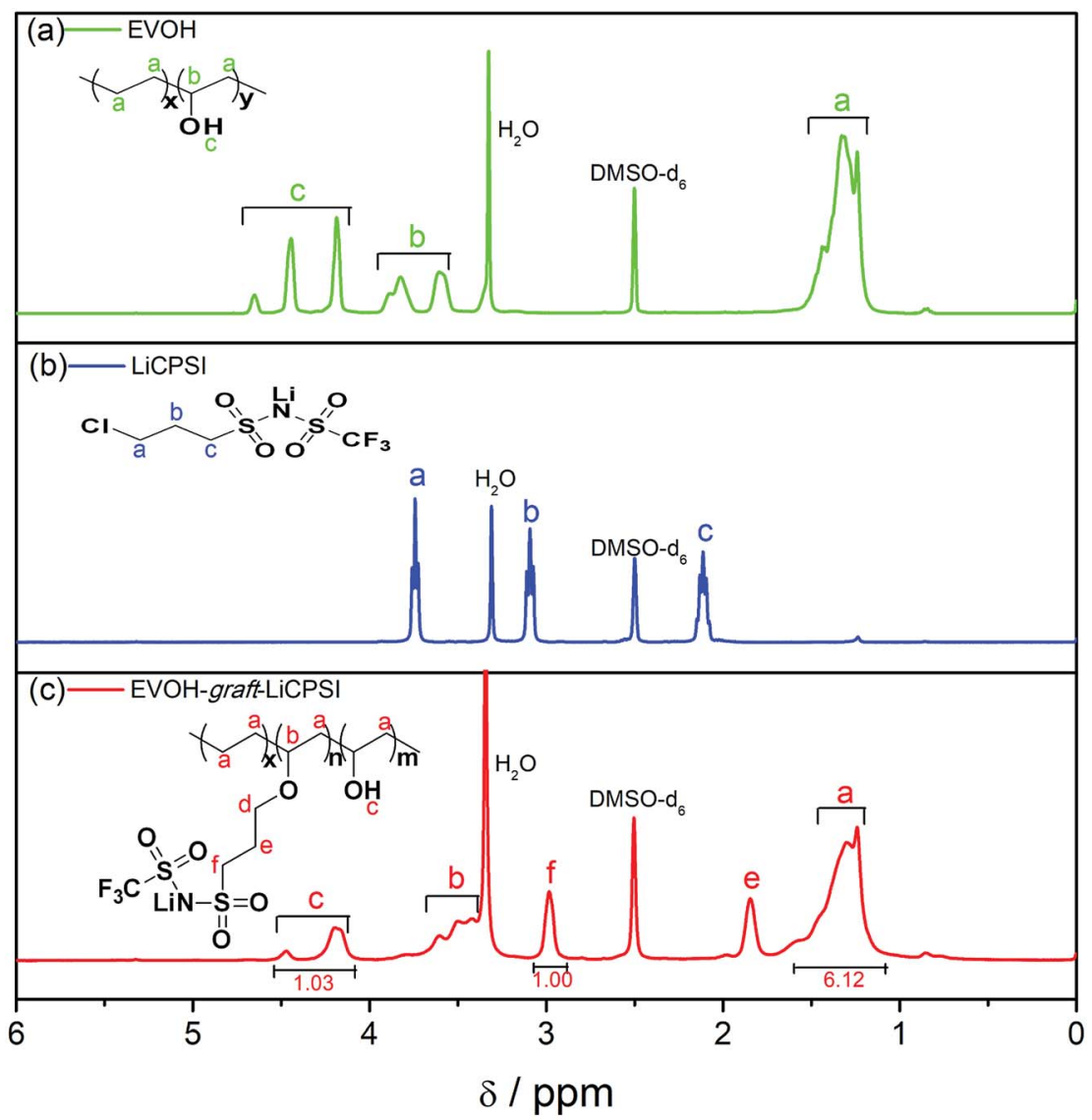

Fig. $2{ }^{1} \mathrm{H}$ NMR spectra (a) EVOH, (b) LiCPSI and (c) EVOH-graft-LiCPSI. 
chemical shift of proton on EVOH. The appearance of peak ' $e$ ' (2.95 ppm) and ' $\mathrm{f}$ ' (1.84 ppm) further demonstrates LiCPSI was successfully grafted on EVOH. Peak ' $\mathrm{d}$ ' is not observed in Fig. 2a, which is probably covered by the water peak at $3.4 \mathrm{ppm}$. The grafted degree is calculated to be $33.3 \%$ based on the integrated area ratio of peak ' $c$ ' to peak ' $\mathrm{f}$ ' $c a .1: 1$. Therefore, the lithium ion exchange capacity of EVOH-graft-LiCPSI is about $2.21 \mathrm{mmol} \mathrm{g}^{-1}$. To rigorously access the lithium ion concentration, the sample was measured by ICP-OES. The result is about $2.27 \mathrm{mmol} \mathrm{g}^{-1}$, slight higher than the theoretical value calculated according to the result of ${ }^{1} \mathrm{H}$ NMR.

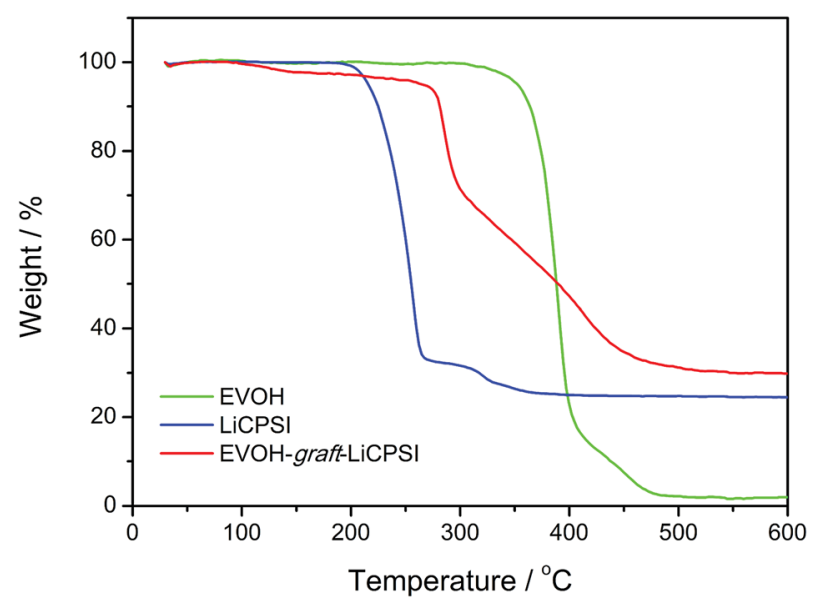

Fig. 3 Thermo-gravimetry analysis of EVOH, LiCPSI and EVOH-graftLiCPSI.
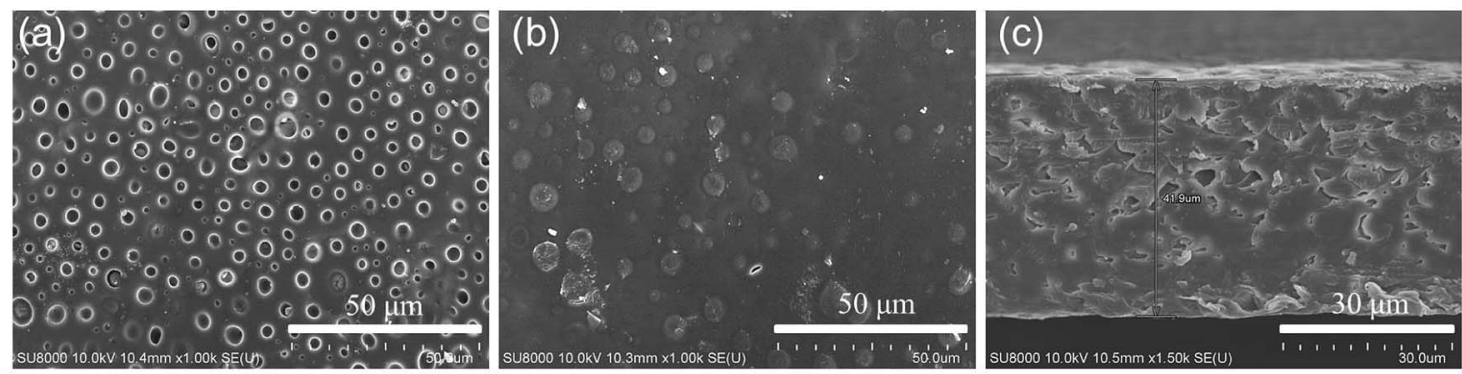

Fig. 4 The SEM images of SIPE. (a) Front surface, (b) back surface and (c) cross section.
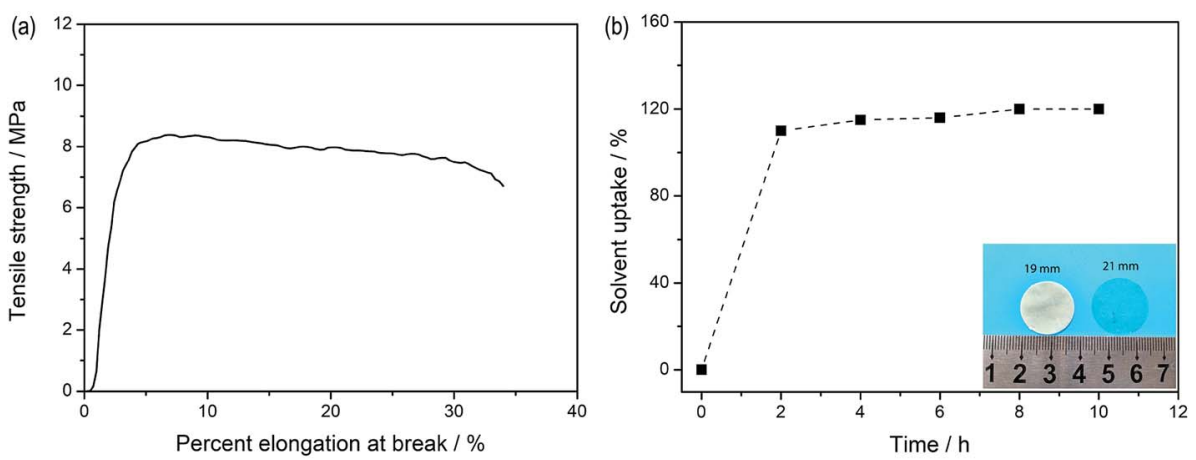

Fig. 5 (a) Tensile test of the dry SIPE and (b) ex situ detection of solvent uptake for SIPE. 
solvent of EC/DMC (v/v, 1:1), the pale yellow membrane gradually become transparent (inset of Fig. 5b), indicating that the prepared SIPE is well compatible with the organic solvent. ${ }^{45}$ The corresponding ex situ detection of the solvent uptake of the SIPE is shown in Fig. 5b. The saturated solvent uptake of $122 \%$ is calculated after soaking for $8 \mathrm{~h}$. It means that the mass of the solvent is about 55 percent of the total gel SIPE. Meanwhile, the diameter is enlarged from the original $19 \mathrm{~mm}$ to $21 \mathrm{~mm}$ after swelling (inset of Fig. 5b) and the surface extension ratio of the swollen film is $22 \%$, probably arising from the stretch of the polymer chain, which is beneficial for the lithium ion transport.

\subsection{Electrochemical performance}

The ionic conductivity, electrochemical stability and lithium ion transference number of the gel SIPE are shown in Fig. 6. To investigate the influence of temperature on the ionic conductivity, the electrochemical impedance spectroscopy (EIS) was carried out from $25{ }^{\circ} \mathrm{C}$ to $80{ }^{\circ} \mathrm{C}$. Fig. 6a displays the initial EIS spectra of the gel SIPE with the inset of the corresponding equivalent circuit. The intercept of a straight line at high frequency is attributed to the bulk resistance $\left(R_{1}\right)$, which is used for calculating the ionic conductivity of the gel SIPE. The ionic conductivities of the gel SIPE at different temperature are shown in Fig. 6b. The ionic conductivity of the gel SIPE is $5.7 \times$ $10^{-5} \mathrm{mS} \mathrm{cm}^{-1}$ at $25^{\circ} \mathrm{C}$ and increases to $1.1 \times 10^{-4} \mathrm{mS} \mathrm{cm}^{-1}$ at $80{ }^{\circ} \mathrm{C}$, showing a typical Arrhenius behavior.

The electrochemical window of gel SIPE is important for the choice of cathode materials. However, most of the reported single ion polymer conductors contains the rigid unsaturated $\mathrm{C}=\mathrm{C}$ bonds, which may influence the electrochemical stability. ${ }^{38,46}$
Herein, to enhance the electrochemical stability of gel SIPE, a bis sulfonyl imide functional group without unsaturated $\mathrm{C}=\mathrm{C}$ bonds was tethered to the flexible saturated polymer backbone of EVOH. As shown in Fig. 6c, the electrochemical stability window is stable up to $4.8 \mathrm{~V}$ (vs. $\mathrm{Li} / \mathrm{Li}^{+}$) (Fig. 7a), which is well-suited for combination with $\mathrm{LiFePO}_{4}$ (ref. 47) and $\mathrm{LiMn}_{2} \mathrm{O}_{4}$ (ref. 47) cathode. The superior electrochemical stability is attributed to the absence of non-saturated bonds in the SIPE. ${ }^{38}$ However, the result is only slight higher than those works contains the rigid unsaturated $\mathrm{C}=\mathrm{C}$ bonds, ${ }^{\mathbf{4 1 , 4 5}}$ which is attributing to the existence of $-\mathrm{OH}$ groups in the polymer main chain.

Lithium ion transference number was determined by a dc polarization combined with impedance spectroscopy using a symmetrical "Li|SIPE $\mid \mathrm{Li}$ " cell. The measurement result is shown in Fig. 7b and the simulated equivalent circuit is also depicted in the inset. Clearly, the current response to the applied static potential polarization is recorded to be more than 7000 seconds. The initial current is $11.21 \mu \mathrm{A}$ and stabilizes at the value of $9.65 \mu \mathrm{A}$ after $200 \mathrm{~s}$. Meanwhile, the corresponding interfacial resistance changes from $272 \Omega$ to $335 \Omega$. Based on the results, the lithium ion transference number was calculated to be 0.88 , indicating a typical single-ion conducting behavior. ${ }^{45}$ The high lithium transference number is owing to the large molecular weight $\mathrm{EVOH}$ as polymer backbones, which greatly restricts the movement of anions.

\subsection{Galvanostatic lithium plating/stripping test}

Galvanostatic cycling test was used to investigate the interface stability between the metal lithium foil and the gel SIPE in a symmetrical " $\mathrm{Li}|\mathrm{SIPE}| \mathrm{Li}$ " cell with the current density of 0.5
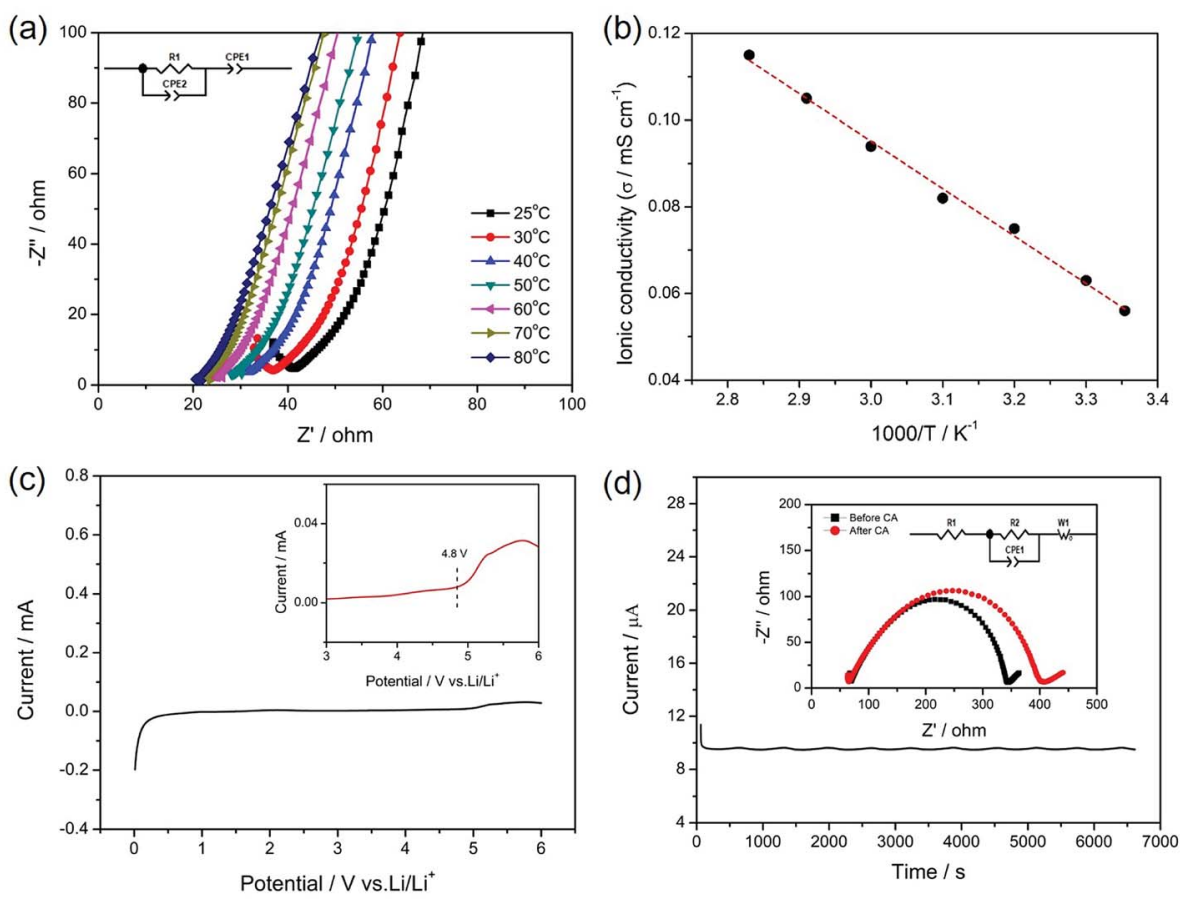

Fig. 6 Electrochemical properties of the gel SIPE. (a) EIS plots of the gel SIPE; (b) ionic conductivity of the gel SIPE under different temperatures; (c) linear sweep voltammetry curve of the gel SIPE and (d) chronoamperometry (CA) of the gel SIPE with the EIS spectra recorded before and after CA test. 


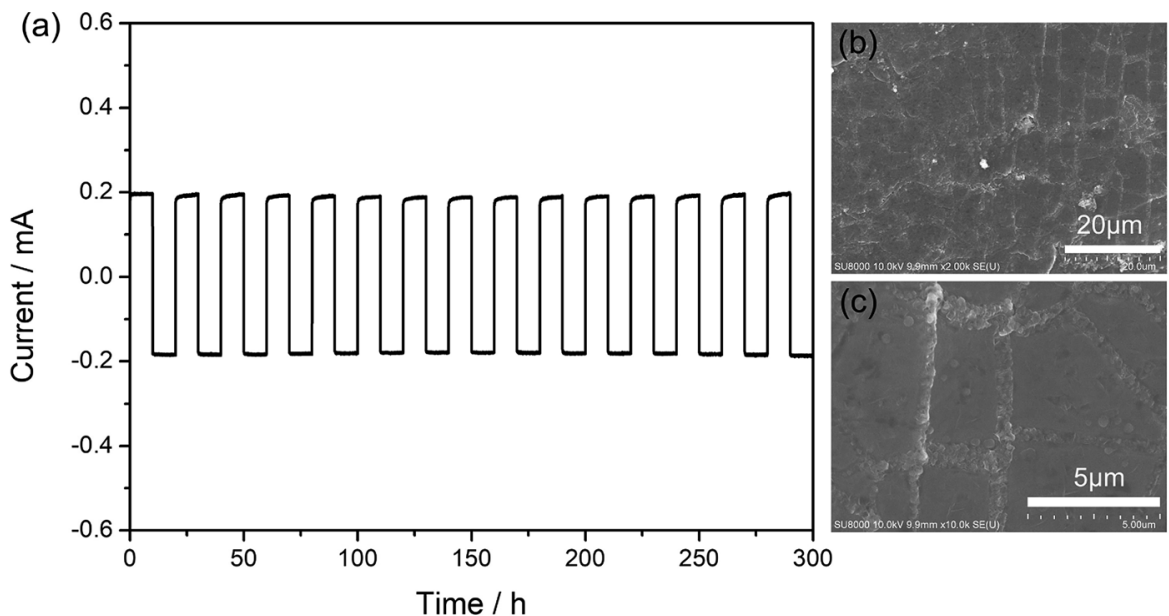

Fig. 7 (a) Galvanostatic lithium plating/stripping cycling profiles of "Li|SIPE|Li" symmetric cell at density of $0.5 \mathrm{~mA} \mathrm{~cm}$ "2. (b) $\&$ (c) SEM image of lithium foil surface after lithium plating/stripping cycling for 300 hours.

$\mathrm{mA} \mathrm{cm}^{-2}$ at room temperature. As shown in Fig. 7a, the polarization potential of the symmetrical cell is $19 \mathrm{mV}$ and almost remains constant for 300 hours, suggesting a stable interface during the testing process. Afterwards, the symmetrical cell was disassembled and the lithium foil was washed by anhydrous DMC. The cycled lithium foil was further investigated by scanning electron microscopy. As illustrated in Fig. $7 \mathrm{~b}$ and $\mathrm{c}$, the lithium foil shows smooth and dense surface morphology after galvanostatic cycling test. The results suggest that the gel SIPE is stable to metal lithium foil in the test period.

\subsection{Battery performance}

To further study the performance of the gel SIPE in the cell, a $\mathrm{LiFePO}_{4} / \mathrm{Li}$ half-cell using the gel SIPE as electrolyte as well as separator was assembled and tested at room temperature. Fig. 8a presents the battery performances at different discharge rates from $0.2 \mathrm{C}$ to $5 \mathrm{C}$. It can be seen that the $\mathrm{LiFePO}_{4} / \mathrm{Li}$ cell delivers a discharge capacity of $123 \mathrm{~mA} \mathrm{~h} \mathrm{~g}{ }^{-1}$ at $0.2 \mathrm{C}$, $115 \mathrm{~mA} \mathrm{~h} \mathrm{~g}^{-1}$ at $0.4 \mathrm{C}, 110 \mathrm{~mA} \mathrm{~h} \mathrm{~g}{ }^{-1}$ at $0.6 \mathrm{C}, 106 \mathrm{~mA} \mathrm{~h} \mathrm{~g}^{-1}$ at $0.8 \mathrm{C}, 101 \mathrm{~mA} \mathrm{~h} \mathrm{~g}^{-1}$ at $1 \mathrm{C}, 96 \mathrm{~mA} \mathrm{~h} \mathrm{~g}^{-1}$ at $1.5 \mathrm{C}, 92 \mathrm{~mA} \mathrm{~h} \mathrm{~g}^{-1}$ at $2 \mathrm{C}$, respectively. When the $\mathrm{C}$-rate turns back to $1 \mathrm{C}$, the discharge capacity can recover to $102 \mathrm{~mA} \mathrm{~h} \mathrm{~g}^{-1}$. Even at higher current rates, it still exhibits high capacities of $84 \mathrm{~mA} \mathrm{~h} \mathrm{~g}^{-1}$ at 3C, $77 \mathrm{~mA} \mathrm{~h} \mathrm{~g}^{-1}$ at $4 \mathrm{C}, 72 \mathrm{~mA} \mathrm{~h} \mathrm{~g}^{-1}$ at $5 \mathrm{C}$. The coulombic efficiency at each $\mathrm{C}$ rate is close to $100 \%$. The corresponding voltage plateaus at each C-rate are shown in Fig. 8b. The longterm cycle performance at $1 \mathrm{C}$ is shown in Fig. $8 \mathrm{c}$. Before test, the battery was initially activated at $0.1 \mathrm{C}$ for several cycles. The discharge capacity at $1 \mathrm{C}$ stabilizes at $100 \mathrm{~mA} \mathrm{~h} \mathrm{~g}^{-1}$ during the (a)

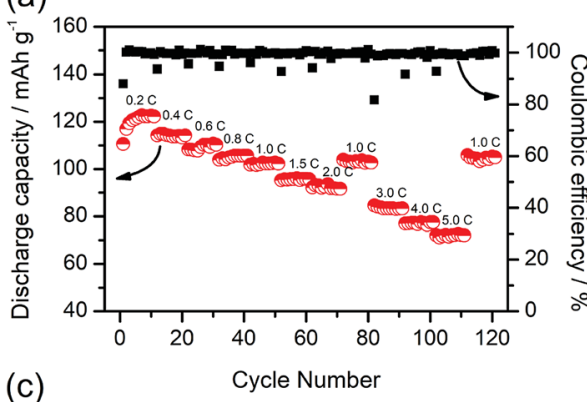

(c) (b)

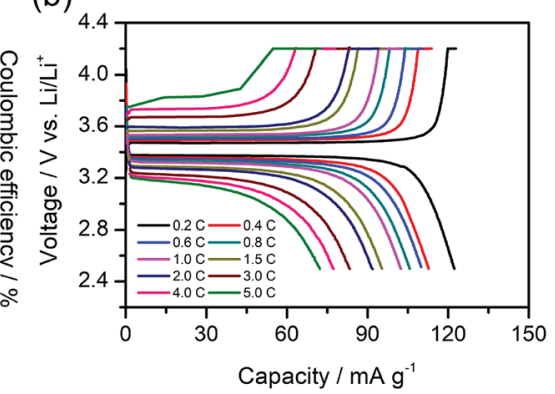

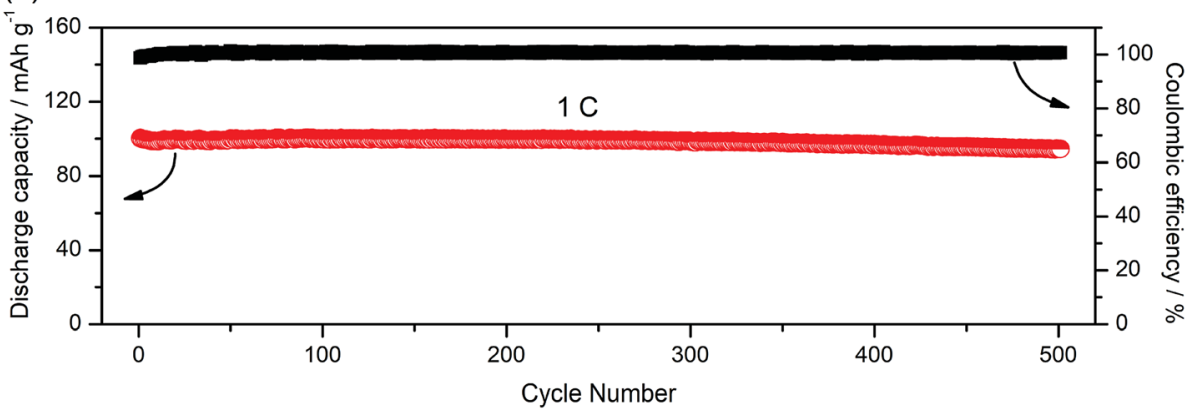

Fig. 8 Battery performances of $\mathrm{LiFePO}_{4} / \mathrm{Li}$ cell at room temperature. (a) Rate performance at various $\mathrm{C}$ rates; (b) charge/discharge curves at different $C$ rate; (c) cycling performances at $1 \mathrm{C}$ for 500 cycles. 
first 250 cycles. After 500 cycles, the discharge capacity still remains at $95 \mathrm{~mA} \mathrm{~h} \mathrm{~g}{ }^{-1}$, suggesting a $95 \%$ retention of the initial discharge capacity. The above battery test results reflect the excellent electrochemical performance of the gel SIPE, which is promising for practical application in lithium ion batteries.

\section{Conclusion}

In this work, we successfully synthesized a novel single ion polymer conductor by grafting the LiCPSI on the EVOH via Williamson's reaction. The SIPE membrane was prepared through blending the EVOH-graft-LiCPSI with the commercial PVDF-HFP. Organic solvent of EC/DMC as plasticizer was added to facilitate lithium ion dissociation and transport, resulting in a high ionic conductivity of $5.7 \times 10^{-5} \mathrm{~S} \mathrm{~cm}^{-1}$ at $25^{\circ} \mathrm{C}$. The gel SIPE exhibits great electrochemical stability $\left(4.8 \mathrm{~V} v s . \mathrm{Li} / \mathrm{Li}^{+}\right)$as well as good mechanical and thermal properties. In addition, due to the high lithium ion transference number of 0.88 , the gel SIPE can effectively suppress the lithium dendrites growth as confirmed by the galvanostatic lithium plating/stripping cycling test. More importantly, the $\mathrm{LiFePO}_{4}$ half-cell assembled with the gel SIPE as the electrolyte as well as the separator delivers $100 \mathrm{~mA} \mathrm{~h} \mathrm{~g}{ }^{-1}$ at $1 \mathrm{C}$ and remains $95 \mathrm{~mA} \mathrm{~h} \mathrm{~g}^{-1}$ after 500 cycles with a high capacity retention of $95 \%$. We believe the SIPE synthesized by side chain grafting of bis sulfonyl imide functional groups to the commercial flexible polymer matrix is a promising choice in the future.

\section{Conflicts of interest}

There are no conflicts to be declared.

\section{Acknowledgements}

The authors gratefully acknowledge support from the Natural Science Foundation of Hubei province of China (No. 2014CFB278) and the Fundamental Research Funds for the Central Universities (No. CUGL140812).

\section{References}

1 M. Amereller, T. Schedlbauer, D. Moosbauer, C. Schreiner, C. Stock, F. Wudy, S. Zugmann, H. Hammer, A. Maurer, R. M. Gschwind, H.-D. Wiemhöfer, M. Winter and H. J. Gores, Prog. Solid State Chem., 2014, 42, 39-56.

2 J. S. Gnanaraj, E. Zinigrad, L. Asraf, H. E. Gottlieb, M. Sprecher, M. Schmidt, W. Geissler and D. Aurbach, J. Electrochem. Soc., 2003, 150, A1533.

3 K. Xu, Chem. Rev., 2004, 104, 4303-4417.

4 C. D. Malliakas, K. Leung, K. Z. Pupek, I. A. Shkrob and D. P. Abrahame, Phys. Chem. Chem. Phys., 2016, 18, 1084610849.

5 L. Long, S. Wang, M. Xiao and Y. Meng, J. Mater. Chem. A, 2016, 4, 10038-10069.

6 L. Yue, J. Ma, J. Zhang, J. Zhao, S. Dong, Z. Liu, G. Cui and L. Chen, Energy Storage Materials, 2016, 5, 139-164.
7 Y. Zhao, R. Tao and T. Fujinami, Electrochim. Acta, 2006, 51, 6451-6455.

8 F. Croce, G. B. Appetecchi, L. Persi and B. Scrosati, Nature, 1998, 394, 456-458.

9 H. Zhang, C. Li, M. Piszcz, E. Coya, T. Rojo, L. M. RodriguezMartinez, M. Armand and Z. Zhou, Chem. Soc. Rev., 2017, 46, 797-815.

10 M. Doyle, T. F. Fuller and J. Newman, Electrochim. Acta, 1994, 39, 2073-2081.

11 D. Golodnitsky, T. A. University and I. Tel Aviv, Encycl. Electrochem. Power Sources, 2009, pp. 112-128.

12 R. Bouchet, S. Maria, R. Meziane, A. Aboulaich, L. Lienafa, J.-P. Bonnet, T. N. T. Phan, D. Bertin, D. Gigmes, D. Devaux, R. Denoyel and M. Armand, Nat. Mater., 2013, 12, 452-457.

13 Y. Lu, M. Tikekar, R. Mohanty, K. Hendrickson, L. Ma and L. A. Archer, Adv. Energy Mater., 2015, 5, 1402073.

14 K. Deng, J. Qin, S. Wang, S. Ren, D. Han, M. Xiao and Y. Meng, Small, 2018, e1801420, DOI: 10.1002/ smll.201801420.

15 Q. Ma, Y. Xia, W. Feng, J. Nie, Y.-S. Hu, H. Li, X. Huang, L. Chen, M. Armand and Z. Zhou, RSC Adv., 2016, 6, 32454-32461.

16 N. Kamaya, K. Homma, Y. Yamakawa, M. Hirayama, R. Kanno, M. Yonemura, T. Kamiyama, Y. Kato, S. Hama, K. Kawamoto and A. Mitsui, Nat. Mater., 2011, 10, 682-686. 17 M. A. T. Marple, B. G. Aitken, S. Kim and S. Sen, Chem. Mater., 2017, 29, 20.

18 N. Rosenkiewitz, J. Schuhmacher, M. Bockmeyer and J. Deubener, J. Power Sources, 2015, 278, 104-108.

19 Q. Liu, Z. Geng, C. Han, Y. Fu, S. Li, Y.-b. He, F. Kang and B. Li, J. Power Sources, 2018, 389, 120-134.

20 W. Zhou, S. Wang, Y. Li, S. Xin, A. Manthiram and J. B. Goodenough, J. Am. Chem. Soc., 2016, 138, 9385-9388.

21 X.-X. Zeng, Y.-X. Yin, N.-W. Li, W.-C. Du, Y.-G. Guo and L.-J. Wan, J. Am. Chem. Soc., 2016, 138, 15825-15828.

22 Z. Zhang, Y. Zhao, S. Chen, D. Xie, X. Yao, P. Cui and X. Xu, J. Mater. Chem. A, 2017, 5, 16984-16993.

23 E. Strauss, S. Menkin and D. Golodnitsky, J. Solid State Electrochem., 2017, 21, 1879-1905.

24 L. Porcarelli, A. S. Shaplov, F. Bella, J. R. Nair, D. Mecerreyes and C. Gerbaldi, ACS Energy Lett., 2016, 1, 678-682.

25 U. H. Choi, S. Liang, M. V. O'Reilly, K. I. Winey, J. Runt and R. H. Colby, Macromolecules, 2014, 47, 3145-3153.

26 M. J. R. Y. J. Shen and P. P. Chu, Solid State Ionics, 2004, 175, 747-750.

27 G. Xu, R. Rohan, J. Li and H. Cheng, RSC Adv., 2015, 5, 32343-32349.

28 Y. Zhang, R. Rohan, Y. Sun, W. Cai, G. Xu, A. Lin and H. Cheng, RSC Adv., 2014, 4, 21163.

29 Y. Zhang, G. Xu, Y. Sun, B. Han, B. T. Teguh Budiono, Z. Chen, R. Rohan and H. Cheng, RSC Adv., 2013, 3, 14934.

30 Y. Sun, R. Rohan, W. Cai, X. Wan, K. Pareek, A. Lin, Y. Zhang and H. Cheng, Energy Technol., 2014, 2, 698-704.

31 C. Cao, Y. Li, Y. Feng, P. Long, H. An, C. Qin, J. Han, S. Li and W. Feng, J. Mater. Chem. A, 2017, 5, 22519-22526. 
32 H. Oh, K. Xu, H. D. Yoo, D. S. Kim, C. Chanthad, G. Yang, J. Jin, I. A. Ayhan, S. M. Oh and Q. Wang, Chem. Mater., 2016, 28, 188-196.

33 H.-Y. Liang, X.-P. Qiu, S.-C. Zhang, W.-T. Zhu and L.-Q. Chen, J. Appl. Electrochem., 2004, 34, 1211-1214.

34 B. Qin, Z. Liu, J. Zheng, P. Hu, G. Ding, C. Zhang, J. Zhao, D. Kong and G. Cui, J. Mater. Chem. A, 2015, 3, 7773-7779.

35 X. Wang, Z. Liu, Q. Kong, W. Jiang, J. Yao, C. Zhang and G. Lei, Solid State Ionics, 2014, 262, 747-753.

36 R. Rohan, K. Pareek, Z. Chen, W. Cai, Y. Zhang, G. Xu, Z. Gao and H. Cheng, J. Mater. Chem. A, 2015, 3, 20267-20276.

37 Y. Liu, Z. Cai, L. Tan and L. Li, Energy Environ. Sci., 2012, 5, 9007-9013.

38 Q. Shi, L. Xue, D. Qin, B. Du, J. Wanga and L. Chen, J. Mater. Chem. A, 2014, 2, 15952-15957.

39 S. Li, A. Mohamed, V. Pande, H. Wang, J. Cuthbert, X. Pan, H. He, Z. Wang, V. Viswanathan, J. F. Whitacre and K. Matyjaszewski, ACS Energy Lett., 2018, 3, 20-27.
40 Q. Pan, Y. Chen, Y. Zhang, D. Zeng, Y. Sun and H. Cheng, J. Power Sources, 2016, 336, 75-82.

41 Y. Chen, Z. Li, X. Liu, D. Zeng, Y. Zhang, Y. Sun, H. Ke and H. Cheng, J. Membr. Sci., 2017, 544, 47-57.

42 J. Evans, C. A. Vincent and P. G. Bruce, Polymer, 1987, 28, 2324-2328.

43 Q. Pan, W. Zhang, M. Pan, B. Zhang, D. Zeng, Y. Sun and H. Cheng, J. Power Sources, 2015, 283, 279-288.

44 Y. Zhang, Y. Chen, Y. Liu, B. Qin, Z. Yang, Y. Sun, D. Zeng, V. Alberto, S. Passerini, Z. Liu and H. Cheng, J. Power Sources, 2018, 397, 79-86.

45 Y. Chen, H. Ke, D. Zeng, Y. Zhang, Y. Sun and H. Cheng, J. Membr. Sci., 2017, 525, 349-358.

46 A. Kraytsberg and Y. Ein-Eli, Adv. Energy Mater., 2012, 2, 922939.

47 H. Zhang, Y. Cao, H. Yang, S. Lu and X. Ai, J. Polym. Sci., Part B: Polym. Phys., 2013, 51, 1487-1493. 